Faculty of Design

2019

Track 5.g Introduction Design with foresight: Strategic anticipation in design research

Jones, Peter, Buehring, Joern, Scupelli, Peter and Bishop, Peter

Suggested citation:

Jones, Peter, Buehring, Joern, Scupelli, Peter and Bishop, Peter (2019) Track 5.g Introduction Design with foresight: Strategic anticipation in design research. In: Academy for Design Innovation Management, 18-21 Jun 2019, London, United Kingdom. Available at http://openresearch.ocadu.ca/id/eprint/2797/

Open Research is a publicly accessible, curated repository for the preservation and dissemination of scholarly and creative output of the OCAD University community. Material in Open Research is open access and made available via the consent of the author and/or rights holder on a non-exclusive basis.

The OCAD University Library is committed to accessibility as outlined in the Ontario Human Rights Code and the Accessibility for Ontarians with Disabilities Act (AODA) and is working to improve accessibility of the Open Research Repository collection. If you require an accessible version of a repository item contact us at repository@ocadu.ca. 


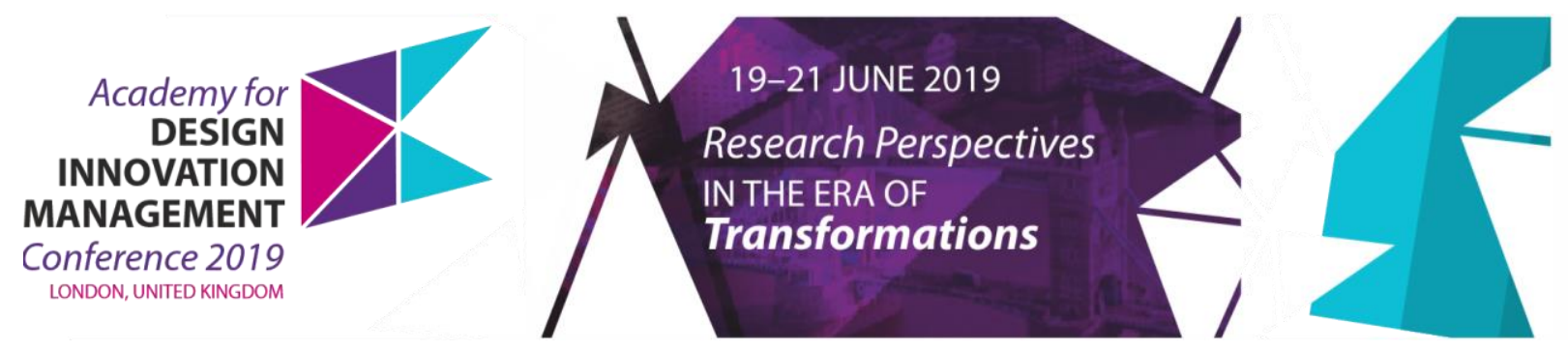

\title{
Track 5.g Introduction: Design with Foresight: Strategic Anticipation in Design Research
}

\author{
BUEHRING Joern ${ }^{\mathrm{a}}$; JONES, Peter ${ }^{\mathrm{b}}$; SCUPELLI Peter ${ }^{\mathrm{c}}$ and BISHOP Peter ${ }^{\mathrm{d}}$ \\ a The Hong Kong Polytechnic University, School of Design, Hong Kong \\ b OCAD University, Canada \\ c Carnegie Mellon School of Design, Carnegie Mellon University, USA \\ d University of Houston, USA (Ret.), Teachthefuture.org \\ doi: $10.33114 /$ adim.2019.5g
}

\section{Introduction}

Global changes in the 21st century appear intractable as social, technological and environmental trends force the contemporary organization to address these uncertainties in vision and strategic direction (Vecchiato, 2012). Enterprises across nearly all sectors of the globalized economy must adapt competitive strategies to anticipate specific political, resource, and market uncertainties that could impact expected growth and broader social benefits (Buehring \& Liedtka, 2018; Wilkinson, Mayer, \& Ringler, 2014). Yet the inclusion of strategic foresight within system, product and service design projects has yet to reach its potential in business enterprises.

Given the uncertainties these often-cited global trends impose, why are decision makers not relying on strategic foresight to inform design decisions and strategic product service development? The most popular business design processes continue to be decidedly short-term reasoning practices: Agile, Lean, and Design Thinking are at least three problematic methodologies that might repel or constrain the uptake of serious futures anticipation. Business foresight practices are commonly relegated to strategy development, thereby informing business models and competitive strategy, but not necessarily the productive design capacity of the enterprise.

While design often addresses complex business problems for today's world and the immediate future, strategic foresight develops alternative scenarios for the futures in which these solutions will exist. Scholars and educators in these core fields are devoting increased attention to the question the most effective organizational process or fit for successful, actionable long-horizon strategies (Bishop, Hines, \& Collins, 2007; Heskett, 2009; Rohrbeck, Battistella, \& Huizingh, 2015; Slaughter, 2002).

The themed track features 4 submissions from nine authors who share important insights, new knowledge, and research outputs relevant to design and innovation management practice and the integration or effective processes of strategic foresight applied to decision-making.

In the paper titled "The Role of Horizon Scanning in Innovation and Design Practice", Isabel Meythaler and Elies Dekoninck focus their investigation on how horizon scanning (HS) is used by practitioners to create foresight for design and innovation. They address two questions: first, how do innovation practitioners spot and act on changes in the business environment, consumer and technological landscape? Second, what methods, tools, and approaches are used? Key insights from sixteen in-depth expert interviews are reported. The authors make three contributions. First, they discuss the role and importance of horizon scanning for innovation and design. Second, they identify dominant methods and approaches used within horizon scanning. Third, they compare the methods typically used by different types of innovation practitioners. The authors report that HS in conjunction with creative and lateral thinking, technology scouting as well as human-centred thinking have two outcomes: first, it facilitates the early detection of emerging trends and technologies and (b)

This work is licensed under a Creative Commons Attribution-NonCommercialShare Alike 4.0 International License. https://creativecommons.org/licenses/by-nc-sa/4.0/ 
it facilitates turning insights into actionable ideas, increasing the likelihood of more successful product development, meaningful innovations, and sustainable competitiveness. These findings are insights and guidance for managing horizon scanning and incorporating it into innovation and technology management strategies.

Challenging predetermined frameworks and biases to planning the future, Timothy Stock and Marie Lena Tupot put forward an argument for designers practicing foresight to overcome their inherent bias toward a world informed by the known and experienced. It is proposed that exploring and planning for the future requires a deeper understanding of a cultural system and language that represents the dynamics between the concrete (known) and abstract worlds, thus needing a mapping system that could help designers to think on multiple abstract levels to anticipate change and make sense of signals, signs, and cultural meaning relevant to their future designs decision-making. This paper is bringing to our attention the need for new design foresight relevant research approaches needed to deal with uncertainty, and the causality of sustainability, and ethical futures considerations. The authors draw on fundamental research design considerations relevant in futures studies, providing relevant examples and case studies in support of the argument that the prevailing design ideology and vocabulary is informed by one of materiality and technology.

In the paper titled "Bringing futures scenarios to life with video animation: A case of disseminating research to non-expert audiences", Jörn Bühring and Nury Vittachi draw attention to research disseminating practices expanding beyond traditional media of publication. That is, research findings in the social sciences, including scenarios produced in futures research, are typically reported in client reports, monographs, white papers and journal articles. The purpose of this paper is to investigate video animation as a way to communicate futures scenarios to nonexpert audiences, corporate decision-makers, and their staff. The process presented in this paper is based on a case study in which academics and designers at a design school took the findings of a financial services futures study and applied storytelling and visualization techniques to bring futures scenarios to life with video animation. The study outlines the four-step process of developing a video animation - the challenge, the exploration, the interactions, and the delivery. Each stage in this process involved techniques and choices to realize the objective, to bring the future to life and make it real for a general audience. The paper concludes with ten recommendations for producing quality videos based on future scenarios.

Finally, Eliana Ferrulli, Caroline Nohra, and Silvia Barbero's RETRACE project cites a systemic design study connecting the functions and methods of strategic foresight to regional planning and development strategies. The challenges her team engages involve the creation of a policy and economy learning network across five regional enterprise communities, with eight partners coordinated by a systemic designer team in the EU-based project. Here the formation of a foresight-based strategy is driven by the necessity to conceive coordinated actions for multi-sectoral transitions to circular economy programs. Coordinated regional engagements such as RETRACE are fairly rare in other parts of the world. Their application of advanced systems-oriented design and foresight as cross-cutting (generalized) approaches in regional development policy provides appropriate methodological pluralism for a creative learning strategy. Many aspects of such a high-complexity engagement might be forbidding to other policy making or design thinking approaches -Such bio-socio-economic transition planning is certainly complex enough of a program. With the project engaging over 70 stakeholders from different countries and regions, touching dozens of companies and planning actors, totally different local economies, it is clear to see the requirement for a systemic approach.

With this eclectic mix of ideas and contributions, the Design with Foresight track explored the value of strategic and creative foresight in design and innovation, together improving the designer's and the organization's learning to adopt new methods in their innovation practices.

\section{References}

Bishop, P., Hines, A., \& Collins, T. (2007). The current state of scenario development: an overview of techniques. foresight, 9(1), 5-25. doi:10.1108/14636680710727516

Buehring, J. H., \& Liedtka, J. (2018). Embracing systematic futures thinking at the intersection of Strategic Planning, Foresight and Design. Journal of Innovation Management, 6(3), 134-152.

Heskett, J. (2009). Creating economic value by design. International Journal of Design, 3(1).

Rohrbeck, R., Battistella, C., \& Huizingh, E. (2015). Corporate foresight: An emerging field with a rich tradition. Technological Forecasting and Social Change, 101, 1-9. doi:10.1016/j.techfore.2015.11.002 
Slaughter, R. (2002). New thinking for a New Millennium: The knowledge base of futures studies: Routledge.

Vecchiato, R. (2012). Environmental uncertainty, foresight and strategic decision making: An integrated study. Technological Forecasting and Social Change, 79(3), 436-447. doi:10.1016/j.techfore.2011.07.010

Wilkinson, A., Mayer, M., \& Ringler, V. (2014). Collaborative futures: Integrating foresight with design in large scale innovation processes-seeing and seeding the futures of Europe. Journal of Futures Studies, 18(4), 1-26. 